Two-Phase Frictional Pressure Drop Multipliers for SUVA R-134a Flowing in a Rectangular Duct

P Vassallo, K Keller

This report was prepared as an account of work sponsored by the United States Government. Neither the United States, nor the United States Department of Energy, nor any of their employees, nor any of their contractors, subcontractors, or their employees, makes any warranty, express or implied, or assumes any legal liability or responsibility for the accuracy, completeness or usefulness of any information, apparatus, product or process disclosed, or represents that its use would not infringe privately owned rights. 


\title{
Two-Phase Frictional Pressure Drop Multipliers for SUVA R-134a Flowing in a Rectangular Duct
}

\author{
Peter Vassallo* and Kurt Keller \\ Lockheed Martin Corporation, Niskayuna, NY 12309
}

\section{Abstract}

The adiabatic two-phase frictional multipliers for SUVA, R-134a flowing in a rectangular duct (with $\left.\mathrm{D}_{\mathrm{H}}=4.8 \mathrm{~mm}\right)$ have been measured for 3 nominal system pressures $\left(0.9 \mathrm{MPa}, \mathrm{T}_{\text {sat }}=35.5^{\circ} \mathrm{C} ; 1.38\right.$ $\mathrm{MPa}, \mathrm{T}_{\text {sat }}=51.8^{\circ} \mathrm{C}$; and $\left.2.41 \mathrm{MPa}, \mathrm{T}_{\text {sat }}=75.9^{\circ} \mathrm{C}\right)$ and 3 nominal mass fluxes $(510,1020$ and 2040 $\mathrm{kg} / \mathrm{m}^{2} / \mathrm{s}$ ). The data is compared with several classical correlations to assess their predictive capabilities. The Lockhart-Martinelli model gives reasonable results at the lowest pressure and mass flux, near the operating range of most refrigeration systems, but gives increasingly poor comparisons as the pressure and mass flux are increased. The Chisholm B-coefficient model is found to best predict the data over the entire range of test conditions; however, there is significant disagreement at the highest pressure tested (with the model over predicting the data upwards of $100 \%$ for some cases). The data shows an increased tendency toward homogenous flow as the pressure and flow rate are increased, and in fact the homogeneous model best predicts the bulk of the data at the highest pressure tested.

Keywords: Two-phase flow; Frictional pressure drop; SUVA R-134a; Two-phase frictional multiplier

\footnotetext{
* Corresponding author. Tel.: +1-518-395-6799; fax: +1-518-395-5353

E-mail address: vassall@kapl.gov
} 


\section{Introduction}

The pressure drop in fluid systems is one of the fundamental parameters of interest to design engineers. The pressure drop in two-phase (i.e., gas-liquid) flow can be dramatically higher than pure liquid flow at the same overall mass flux, easily one or two orders of magnitude higher. Two-phase multipliers have been used to account for this and provide a simple means of estimating the relative increase in pressure drop due to the presence of the gas phase.

A number of correlations and analyses have been developed to predict the two-phase multipliers for a variety of two-phase flows. The simplest analysis is perhaps the homogeneous approximation, where both phases are assumed to flow with the same average velocity. This approximation may be useful at high mass flux or high pressure, where the slip ratio (gas velocity relative to liquid velocity) is expected to be low, but in general the homogeneous model will underpredict the actual pressure drop in real systems. Martinelli and Nelson (1948) and Lockhart and Martinelli (1949) were early proponents of a separated flow model, where each phase is assumed to flow at different average velocities. They developed a correlation which performed well for different fluids at low mass flux, but did not allow for sensitivity to mass flux. Baroczy (1968) captured the mass flux effect as well as the effect of fluid property by fitting a large set of data taken in different fluids and at different flow rates; however the graphical form of his correlation did not lend itself to easy application. Chisholm (1973) combined the results of Lockhart and Martinelli and Baroczy with a new analysis to obtain an analytical expression for pressure drop which is more convenient to use than the Baroczy plots. Friedel (1979) later examined a large data base to develop his own correlation. Most of the data used to develop the above correlations were obtained from air-water and steam-water systems.

Recently, there has been interest in understanding the pressure drop for refrigerant fluids, in particular for refrigerant systems where the coolant flows through small tubes or microchannels (Jung and 
Radermacher, 1989; Tran et al,. 1996, 2000; Ould et al., 2002; Garimella et al., 2003). Tran et al. (2000) have considered small tubes as those under about $3 \mathrm{~mm}$ in diameter. The general operational range of interest in most refrigerant systems encompasses pressures under $1 \mathrm{MPa}$ and mass fluxes under $600 \mathrm{~kg} / \mathrm{m}^{2} / \mathrm{s}$. SUVA R-134a, a substitute for Freon used commonly in air conditioning systems, has been investigated by several researchers in this area (Tran et al., 2000; Ould et al., 2002; Garimella et al., 2003). Knowledge of refrigerant fluid behavior at higher pressures and mass flux is also important for scaling studies between the refrigerant modeling fluid and pertinent steam-water applications (Kirouac et al., 1999).

Many of the previous studies comparing frictional pressure drop with correlations involved using analytic expressions for void fraction to obtain acceleration pressure drop in heated flow which was then subtracted from the measured total pressure drop. This introduces some uncertainty into the measured frictional component. In this work, the pressure drop for SUVA in adiabatic flow is examined using gamma densitometer void fraction measurements to directly determine the frictional multiplier; this data is then compared with several available correlations across a wide range of mass flux and pressure to assess the quality of the predictions.

\section{Review of $\Delta \mathrm{P}$ Predictors}

The two-phase frictional multiplier is defined as:

$$
\Phi_{l o}^{2}=\frac{\Delta P_{2 \phi}}{\Delta P_{l o}}
$$

where the subscript $2 \phi$ refers to the two-phase flow condition and the subscript $l o$ indicates the condition with only liquid flowing in the channel (at a mass flow rate $=G A$ ).

\subsection{Homogeneous model}

The homogeneous model is obtained by assuming no slip between the gas and liquid phases (i.e., $V_{l}=V_{g}$ ): 
$x=\frac{\dot{m}_{v}}{\dot{m}_{\text {total }}}=\frac{\rho_{v} \alpha}{(1-\alpha) \rho_{l}+\alpha \rho_{v}}$

$\Phi_{l o}^{2}=\frac{\rho_{l}}{\rho_{2-\phi}} \frac{f_{2-\phi}}{f_{l o}}$

where

$\rho_{2-\phi}=(1-\alpha) \rho_{l}+\alpha \rho_{v}$

Using the Blasius equation for friction factor:

$f=0.316(\mathrm{Re})^{-0.25}$

the two-phase multiplier is:

$\Phi_{l o}^{2}=\frac{\rho_{l}}{\rho_{2-\phi}}\left(\frac{\mu_{2-\phi}}{\mu_{l}}\right)^{0.25}$

The equation proposed by McAdams (1942) is used to evaluate $\mu_{2-\phi}$ :

$\frac{1}{\mu_{2-\phi}}=\frac{x}{\mu_{v}}+\frac{(1-x)}{\mu_{l}}$

Note this allows for the proper viscosities at $x=0$ and $x=1$. The final 2-phase homogeneous friction multiplier is:

$\Phi_{l o}^{2}=\left[1+x\left(\frac{\left(\rho_{l}-\rho_{v}\right)}{\rho_{v}}\right)\right]\left[1+x\left(\frac{\left(\mu_{l}-\mu_{v}\right)}{\mu_{v}}\right)\right]^{-0.25}$

\subsection{Lockhart-Martinelli model}

Although the homogeneous model may perform adequately in flow conditions where the slip ratio is low (e.g. high pressure or high mass flux conditions), it is not generally applicable for most 2-phase flows. A better approach has been to allow for a velocity difference between the two phases. This may be accomplished using a separated flow model, where the velocity of each phase is assumed to 
be uniform at any axial cross section (though not necessarily equal). For steady, one dimensional, adiabatic flow through a channel of constant cross sectional area, the total pressure drop is given as:

$$
\frac{d P}{d z}=\Phi_{l}^{2}\left(\frac{d P}{d z}\right)_{l}-\left[(1-\alpha) \rho_{l}+\alpha \rho_{v}\right] g
$$

where the subscript $l$ indicates the condition with liquid flowing alone in the channel (at a mass flow rate $=G(1-x) A)$. Lockhart and Martinelli (1949) developed curves for $\Phi_{l}^{2}$ using data for adiabatic 2phase flow in horizontal tubes, which for turbulent flow can be written as:

$$
\Phi_{l}^{2}=\frac{(d P / d z)_{2 \phi}}{(d P / d z)_{l}}=\left[1+\frac{20}{X_{t t}}+\frac{1}{X_{t t}^{2}}\right]
$$

where $X_{t t}$ is the Martinelli parameter, assuming both the gas and liquid phases are in the turbulent flow regime, defined as:

$$
X_{t t}=\left[\frac{(d P / d z)_{l}}{(d P / d z)_{v}}\right]^{1 / 2}
$$

For the separated 2-phase flow model, the frictional gradients may be computed as:

$$
\begin{aligned}
& (d P / d z)_{l}=-\frac{1}{2} f_{l} \frac{G^{2}(1-x)^{2}}{\rho_{l} D} \\
& (d P / d z)_{v}=-\frac{1}{2} f_{v} \frac{G^{2} x^{2}}{\rho_{v} D} \\
& f_{l}=0.316\left(\frac{G(1-x) D}{\mu_{l}}\right)^{-0.25} \\
& f_{v}=0.316\left(\frac{G x D}{\mu_{v}}\right)^{-0.25}
\end{aligned}
$$

Substituting:

$$
X_{t t}=\left(\frac{\rho_{v}}{\rho_{l}}\right)^{0.5}\left(\frac{\mu_{l}}{\mu_{v}}\right)^{0.125}\left(\frac{1-x}{x}\right)^{0.875}
$$


This compares well with the expression for $X_{t t}$ developed by Martinelli and Nelson using data for flow boiling inside tubes (1948). The relationship between the multipliers $\Phi_{l}^{2}$ and $\Phi_{l o}^{2}$ may be determined using Eqs. 19 and 21 and similar expressions where liquid only flows through the duct (i.e. $l o: x=0$ ):

$\Phi_{l o}^{2}=\left[1+\frac{20}{X_{t t}}+\frac{1}{X_{t t}^{2}}\right](1-x)^{1.75}$

\subsection{Chisholm B-Coefficient model}

For fully rough surfaces, where the friction factor is not a function of Reynolds number (i.e., the exponent, $n=0$ in Eq. (4)), Chisholm (1973) derived a modified form of Eq. (9) as:

$$
\frac{\Delta P_{2 \phi}}{\Delta P_{l o}}=1+\frac{C}{X_{t t}}+\frac{1}{X_{t t}^{2}}
$$

with

$$
C=\frac{1}{S} \sqrt{\frac{\rho_{l}}{\rho_{g}}}+S \sqrt{\frac{\rho_{g}}{\rho_{l}}}
$$

and the slip ratio, $S$, defined as:

$$
S=\frac{V_{g}}{V_{l}}
$$

A property coefficient was introduced:

$$
\Gamma=\sqrt{\frac{\Delta P_{g o}}{\Delta P_{l o}}}=\left(\sqrt{\frac{\rho_{l}}{\rho_{g}}}\right)\left(\frac{\mu_{g}}{\mu_{l}}\right)^{n / 2} \text { for smooth walls }
$$

which is similar to the coefficient used by Baroczy (1968):

$$
\frac{\rho_{g}}{\rho_{l}}\left(\frac{\mu_{g}}{\mu_{l}}\right)^{0.2}
$$

Chisholm transformed Eq. (25) to the general form for smooth tubes (i.e., $n \neq 0$ ) approximately as:

$\Phi_{l o}^{2}=1+\left(\Gamma^{2}-1\right)\left\{B x^{(2-n) / 2}(1-x)^{(2-n) / 2}+x^{2-n}\right\}$ 
$B=\frac{C \Gamma-2^{n-2}+2}{\Gamma^{2}-1}$

Using the Baroczy correlation as the basis, a plot of $C$ vs. $\Gamma$ was obtained, then transformed into a plot of B vs. $\Gamma$ and $G$. The final recommendations for B was a compromise between Baroczy, Lockhart-Martinelli and Chisholm such that the greatest estimate of pressure gradient was obtained.

Table 1 summarizes the values of B used in the current application.

\begin{tabular}{|c|c|}
\hline$G\left(\mathrm{~kg} / \mathrm{m}^{2} \mathrm{~s}\right)$ & B \\
\hline$<500$ & 4.8 \\
\hline $500<G<1900$ & $2400 / G$ \\
\hline$>1900$ & $55 / G^{0.5}$ \\
\hline
\end{tabular}

Table 1. Values of B for Chisholm correlation for smooth tubes and $\Gamma \leq 9.5$

\subsection{Friedel model}

The last correlation considered is the Friedel correlation (1979), given as:

$\Phi_{l o}^{2}=E+\frac{3.24 F H}{F r_{h}^{0.045} W e_{L}^{0.035}}$

where

$F r_{h}=\frac{G^{2}}{g D_{H} \rho_{h}^{2}}$

$E=(1-x)^{2}+x^{2} \frac{\rho_{l} f_{g}}{\rho_{g} f_{l}}$

$F=x^{0.78}(1-x)^{0.224}$

$H=\left(\frac{\rho_{l}}{\rho_{g}}\right)^{0.91}\left(\frac{\mu_{g}}{\mu_{l}}\right)^{0.19}\left(1-\frac{\mu_{g}}{\mu_{l}}\right)^{0.7}$

The liquid Weber number $W e_{L}$ is defined as:

$W e_{L}=\frac{G^{2} D_{H}}{\sigma \rho_{h}}$ 
with the homogeneous density $\rho_{h}$ given as:

$$
\frac{1}{\rho_{h}}=\left(\frac{x}{\rho_{g}}+\frac{1-x}{\rho_{l}}\right)
$$

\section{Experimental System}

A schematic layout of the SUVA R-134a loop is shown in Fig. 1. A circulating canned rotor pump provides the flow, which is passed through a preheater, then split into 3 independent inlet flow zones before entering the test section. Each inlet zone contains a Venturi flow meter, throttling valve and inlet heater. The inlet flow was distributed among the 3 inlet zones depending on the total flow rate. At the highest mass flux (i.e., $\mathrm{G}=2040 \mathrm{~kg} / \mathrm{m}^{2} / \mathrm{s}$ ), the inlet flow was evenly divided among the 3 inlet zones, while for the lower total flow rates, a single center inlet zone was normally used. The use of inlet zoning improves the accuracy of the inlet flow measurement, especially at the lower flow rates where the Venturi range is better optimized. The fluid entering the Venturi was always at least $5^{\circ} \mathrm{C}$ subcooled liquid. Before entering the test section, the flow enters a plenum consisting of a series of screens, a nozzle and a flow straightener, as shown in Fig. 2. This effectively removes gross maldistribution of flow due to the inlet zones (i.e., the manner in which the flow enters the test section has no discernable effect on the measurements taken at downstream locations). Later pressure drop comparisons in the last half of the test section (given in Section 4.1) reveal developed flow for purposes of frictional pressure drop analysis. The test section itself is a vertical, $1.22 \mathrm{~m}$ long rectangular duct with a width of $57.2 \mathrm{~mm}$ and thickness of $2.5 \mathrm{~mm}$. 


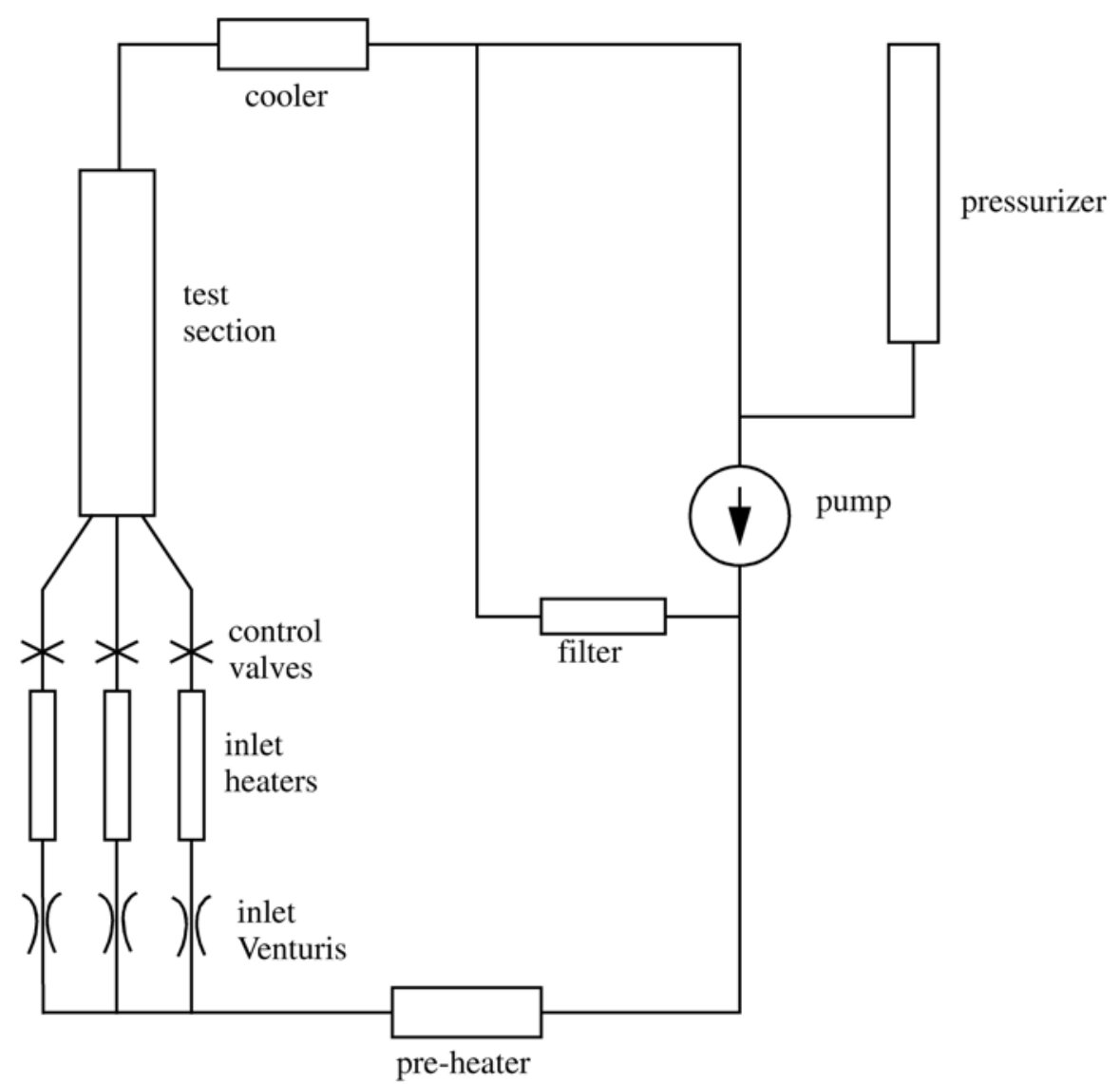

Figure 1. SUVA test loop. Test section details are provided in Fig. 2.

The $\Delta \mathrm{P}$ data described herein was gathered as part of a larger fundamental study of two-phase flow where useful 2-D flow visualization was required (Kirouac et al., 1999; Trabold et al., 1999; Vassallo et al., 2001; Kumar et al., 2003). As such, the test section was designed to accommodate a series of planar windows, four on each side, to form the flow duct and facilitate good flow visualization with high speed or still photography. The windows were optically clear fused silica, each $3.8 \mathrm{~cm}$ thick by 7.6 $\mathrm{mm}$ wide by $27.9 \mathrm{~cm}$ long. Each window has 3 transparent, conductive indium-tin-oxide films vacuum-deposited on the inside surface to allow for direct heating of the fluid. For the bulk of the data shown here, the voids in the test section were created by using the inlet heaters, with no power applied to the window heaters (referred to as adiabatic testing). For some limited data, the window heaters in the first 3 test section elevations were used to create voids (uniform power among all 18 heater strips), while the last elevation remained unheated (referred to as heated testing). Between the window elevations, as well as at the inlet and exit of the test section, $2.54 \mathrm{~cm}$ diameter ports are 
located, which permit access to the flow for various instruments. For these tests, thermocouple rakes were inserted into the inlet and exit ports, while the remaining ports were left open.

The flow exiting the test section enters an exit plenum, then is passed through a large $\mathrm{CO}_{2}$ heat exchanger to remove the voids before entering the suction side of the pump. A pressurizer is used to maintain system pressure. A bypass line passing through a 10 micron particulate filter is left open at low flow rate to constantly remove solid contaminants from the loop. The SUVA itself was processed using a distillation method to assure that the contamination level was minimized. The distillation method was found to be particularly good for removing unwanted oil from the SUVA, and maintained the purity level consistent with the original supply of SUVA (i.e., 99.9\% pure).

\subsection{Loop and Test Section Instrumentation}

A summary of the loop and test section instrumentation, along with their associated uncertainties, is given in Table 2. The absolute and differential pressures were measured with standard Rosemount transducers. The system pressure was measured near the test section exit (either $\mathrm{X}=117.2 \mathrm{~cm}$ or $123.3 \mathrm{~cm}$ ) as illustrated in Fig. 2. Single Type $\mathrm{K}$ thermocouples were installed at the inlets to the inlet heaters and a rake of up to 9 Type $\mathrm{K}$ thermocouples was installed at the test section inlet to measure average inlet temperatures. The inlet temperatures to the heaters were generally less than $10^{\circ} \mathrm{C}$ subcooled. The system heat losses were determined via single phase liquid data runs flowing through an unheated loop (and test section) by measuring the temperature difference between inlet and exit at various pressures and flow rates. This data was used to develop a correlation of the form:

$Q_{\text {loss }}=\frac{A\left(\bar{T}-T_{\text {ambient }}\right)^{B}}{\operatorname{Re}^{C}}$

where $\bar{T}$ is the average temperature between inlet and exit (i.e., $\left.\left(T_{\text {in }}+T_{\text {exit }}\right) / 2\right)$, Re is the Reynolds number, and $A, B$ and $C$ are coefficients obtained by curve fitting the heat loss data. Similar heat loss equations were established for the inlet heaters, the inlet plenum and the test section. The 
uncertainty in heat loss was estimated to be $+/-54 \mathrm{~W},+/-22 \mathrm{~W}$ and $+/-6 \mathrm{~W}$ for the test section, inlet heater and inlet plenum, respectively.

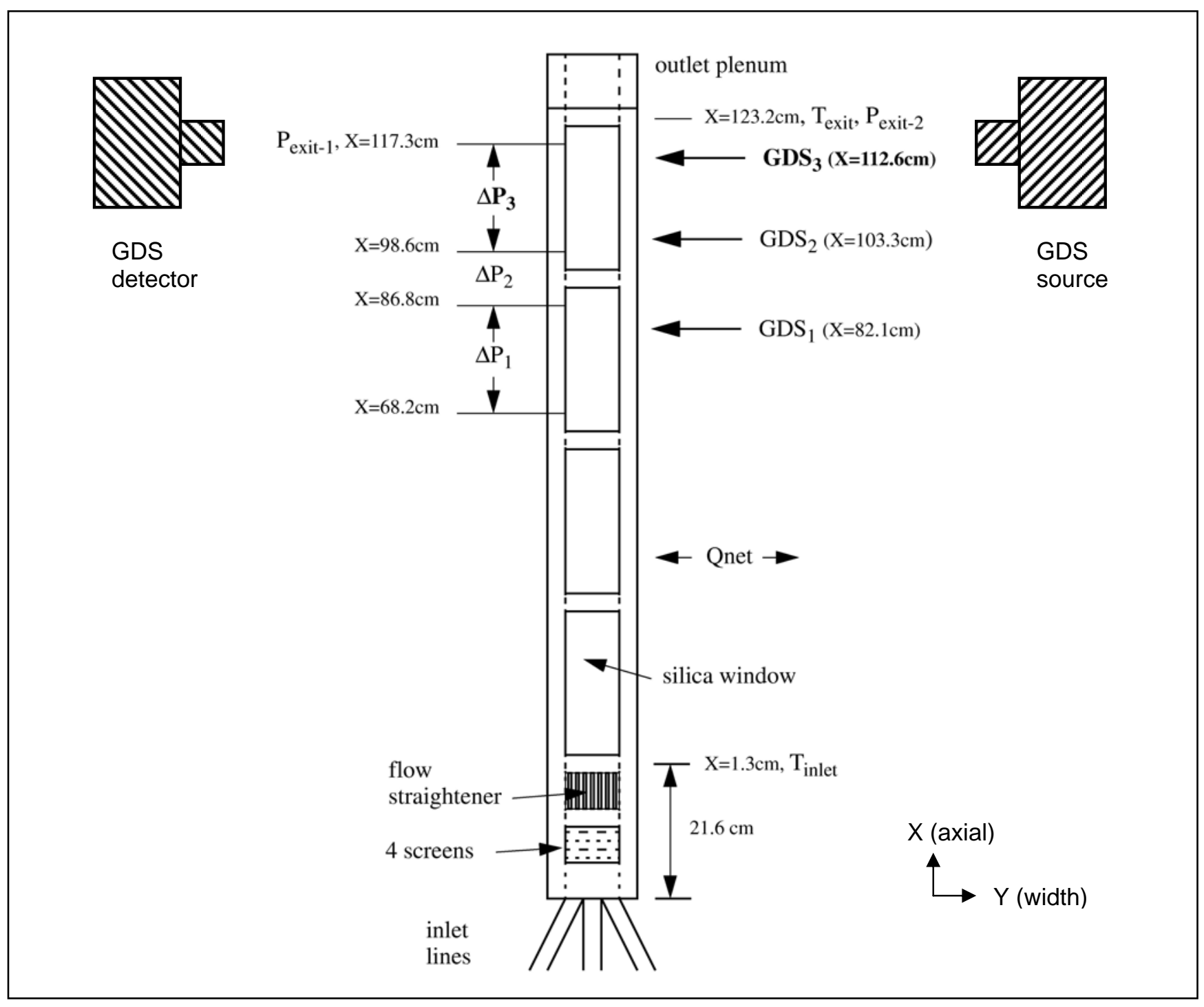

Figure 2. Test section schematic and experimental measurement locations. $\Delta \mathrm{P}$ refers to differential pressure drop and GDS refers to gamma densitometer measurements of average void fraction. 


\begin{tabular}{|l|l|l|}
\hline Measurement & Instrument(s) & Uncertainty \\
\hline Inlet flow rates & $\begin{array}{l}\text { Venturi + Rosemount } \\
\text { Model 3051C }\end{array}$ & $+/-13.1 \mathrm{~kg} / \mathrm{m}^{2} / \mathrm{s}$ \\
\hline Loop pressure & $\begin{array}{l}\text { Rosemount } \\
\text { Model 1151 }\end{array}$ & $+/-19.3 \mathrm{kPa}(+/-2.8 \mathrm{psi})$ \\
\hline Differential pressure & $\begin{array}{l}\text { Rosemount } \\
\text { Model 3051C }\end{array}$ & $\begin{array}{l}+/-0.33 \mathrm{kPa} / \mathrm{m} \text { for }<19.5 \mathrm{kPa} / \mathrm{m} \\
+/-0.42 \mathrm{kPa} / \mathrm{m} \text { for }>19.5 \mathrm{kPa} / \mathrm{m}\end{array}$ \\
\hline $\begin{array}{l}\text { Inlet heater inlet } \\
\text { temperature }\end{array}$ & $\begin{array}{l}\text { Special grade Type } \mathrm{K} \\
\text { thermocouple }\end{array}$ & $+/-1 .^{\circ} \mathrm{C}$ \\
\hline $\begin{array}{l}\text { Test section inlet } \\
\text { temperature }\end{array}$ & $\begin{array}{l}\text { Special grade Type } \mathrm{K} \\
\text { thermocouples }\end{array}$ & $+/-0.6{ }^{\circ} \mathrm{C}$ \\
\hline Inlet heater power & Wattmeters & $+/-5 \%$ \\
\hline Test section power & Wattmeters & $+/-130 \mathrm{~W}$ \\
\hline Heat loss & Correlated data & $+/-82 \mathrm{~W}$ maximum \\
\hline Void fraction & Gamma densitometer & $\begin{array}{l}\text { random: }+/-0.02 \text { absolute } \\
\text { bias: }-0.03 \text { absolute }\end{array}$ \\
\hline
\end{tabular}

Table 2. Summary of Measurement Instrumentation

\section{Gamma Densitometer System (GDS)}

The average cross-sectional void fraction in the test section was measured using a gamma densitometer system (GDS), as depicted in Fig. 2. This system includes a 9 curie Cesium-137 gamma source on one side of the test section and a $5.1 \mathrm{~cm}$ square sodium-iodide gamma detector on the opposite side. The GDS system was accurately centered in the test section by observing the sharp change in count rate as the GDS beam was traversed across the narrow dimension of the duct. The collimator on the source cask provided a $19 \mathrm{~mm}$ high (in the $X$ direction) by $4.3 \mathrm{~mm}$ wide (in the $\mathrm{Z}$ direction) gamma beam so that, when centered, the entire cross section of the flow could be interrogated at various streamwise positions. The GDS allows a direct measurement of the density of a two-phase mixture in the path of the gamma beam through the following relationship:

$$
\rho_{2 \phi}=\frac{\ln \left(\frac{I_{O}}{I}\right)}{A t}
$$

where $I_{O}$ and At are calibration constants obtained from gamma count measurements at each desired measurement position with an empty test section and a sub-cooled liquid filled test section, 
respectively. The count rate $I$ is that measured for the two-phase test condition. The two-phase density is related to the void fraction and vapor and liquid densities through the following relationship:

$\rho_{2 \phi}=(1-\alpha) \rho_{l}+\alpha \rho_{g}$

where $\alpha$ is the void fraction, $\rho_{l}$ is the liquid phase density, and $\rho_{g}$ is the gas phase density. Solving for $\alpha$ yields:

$\alpha=\frac{\rho_{l}-\rho_{2 \phi}}{\rho_{l}-\rho_{g}}$

The liquid and vapor phase densities were determined based on the saturation properties at the measured test section exit pressure.

Most of the void fraction data was taken at $\mathrm{X}=112.6 \mathrm{~cm}$, corresponding to $\mathrm{GDS}_{3}$ in Fig. 2 . For some of the runs, data was taken at $X=103.3 \mathrm{~cm}\left(G_{D S}\right)$ instead. Also, some selected data was taken at $X=82.1 \mathrm{~cm}\left(G_{1}\right)$ along with the $\mathrm{GDS}_{3}$ data, which allows for subsequent comparisons in the adiabatic flow cases. The variety in GDS measurement locations was due to differences in test specifications throughout the years of testing.

Several sources of bias error were considered for the GDS measurements:

- Because some of the GDS beam bypasses the fluid portion of the test section (about $40 \%$ of the beam thickness) a small bias is introduced into the measurement described in Eq. (32). The magnitude of this bias was determined theoretically using measured values of $I_{O}$ and $A t$ and was found to be about $+2 \%$ in absolute void fraction for a measured average void fraction of $50 \%$. That is, for $50 \%$ void in the test section, the raw GDS measurement is $48 \%$ (this corresponds to $28 \%$ GDS counts bypassing the fluid). The magnitude of this bias decreases quadratically on either side of the maximum, approaching $0 \%$ bias at the all liquid or all vapor 
flow conditions. This calculated bias was added to the raw GDS data in order to remove this known effect.

- As described by Stahl and von Rohr (2004), a measured bias will exist if the flow is stratified in either space or time. This situation occurs if the GDS beam traverses the liquid or vapor phase only as it passes from the source to detector. For example, if an idealized slug distribution in time is considered with equal increments of pure vapor or pure liquid passing through the GDS beam, the measured average void fraction will be somewhat higher than the true value. This is due to the logarithmic form of Eq. (32) and the fact that counts through the vapor phase alone are effectively weighted more heavily than the liquid phase alone. The magnitude of this bias was estimated using realistic void profiles in space and time and real experimental parameters of $I_{o}$ and $A t$ and was found to be about $-3 \%$ in absolute void for the worst case situation. Like the bypass error described above, this particular bias is maximized near average void fractions of $50 \%$ and decreases at lower and higher average void fractions; unlike the previous bias, it acts in the opposite direction. That is, the measured value for $50 \%$ actual void would be 53\%. This bias was included in Table 2 and will be considered in the uncertainty analysis provided in Section 4.

\section{Pressure Drop}

Rosemount pressure transducers were used to measure the pressure drop between selected axial positions in the test section. In all cases, the pressure drop in the uppermost window elevation (i.e., from $X=98.6$ to $X=117.3 \mathrm{~cm}$ or $\Delta \mathrm{P} 3$ ) was measured; for some cases, the pressure drop in the third window elevation (from $\mathrm{X}=68.2$ to $\mathrm{X}=86.8 \mathrm{~cm}$ or $\Delta \mathrm{P} 1$ ) as well as across the third bridge insert (from $\mathrm{X}=86.8$ to $\mathrm{X}=98.6 \mathrm{~cm}$ or $\Delta \mathrm{P} 2)$ was also measured. Stainless steel tubing, $6.35 \mathrm{~mm}$ inner diameter, connected pressure taps along the test section edge to the Rosemount transducers. 
Two Rosemount transducers calibrated at different pressure ranges were available to optimize the measurements. The liquid head in the pressure lines $\left(\rho_{l}^{\prime} g h\right)$ was added to the $\Delta \mathrm{P}$ measurements to obtain the 2-phase pressure drop within the test section as follows:

$\Delta P_{\text {Rosemount }}=P_{A}-\left(P_{B}+\rho_{l}^{\prime} g h\right)$

where $P_{A}$ and $P_{B}$ are upstream and downstream pressure positions within the test section and $\rho_{l}^{\prime}$ is taken to be the liquid density at ambient temperature outside the test section. Eq. (35) may be rewritten as:

$\Delta P_{\text {Rosemount }}+\rho_{l}^{\prime} g h=\Delta P_{f}+\Delta P_{a}+\Delta P_{h}$

The pressure drop within the test section includes frictional, acceleration and gravity components, as indicated by the right hand side of Eq. (36). For these tests, the pressure drop measurements were taken over unheated lengths (where the void fraction and flow quality gradients were near zero) so that the acceleration component could be neglected. Using the GDS measured average void fraction, $\bar{\alpha}$, the frictional component of the pressure drop was determined as:

$\Delta P_{f}=\Delta P_{\text {Rosemount }}+\rho_{l}^{\prime} g h-\left(\rho_{l}(1-\bar{\alpha}) g h+\rho_{v} \bar{\alpha} g h\right)$

where $\rho_{l}, \rho_{v}$ are taken to be the saturation phase densities corresponding to the test section exit pressure. The average ambient temperature for all the runs was $25.9{ }^{\circ} \mathrm{C}$ with a standard deviation of $2.9^{\circ} \mathrm{C}$.

\section{Flow Quality}

The exit quality was calculated as follows:

$x_{\text {out }}=\frac{\left\lfloor Q_{\text {net }}-\dot{m}\left(h_{l, \text { out }}-h_{l, \text { in }}\right)\right\rfloor}{\dot{m}\left(h_{v, \text { out }}-h_{l, \text { out }}\right)}$

where $h_{v, \text { out }}=$ saturation vapor enthalpy at test section exit based on exit pressure

$h_{l, \text { out }}=$ saturation liquid enthalpy at test section exit based on exit pressure 


$$
\begin{aligned}
& h_{l, \text { in }}=\text { subcooled liquid enthalpy at heater inlet based on inlet temperature } \\
& Q_{\text {net }} \quad=\text { net heat input to the system, from heater inlet to test section exit }
\end{aligned}
$$

For adiabatic testing, the system included inlet heaters and unheated test section, whereas for heated testing, the system included the test section only. The uncertainty in the calculated quality will be given in Section 4.1.

\section{Results and Discussion}

Data was taken for 3 nominal flow rates and 3 nominal pressures. Table 3 summarizes the actual mean, deviations and number of points for the conditions measured.

\begin{tabular}{|l|l|l|l|l|}
\hline Parameter & Nominal Value & Actual Mean Value & Actual Deviation & Data Points \\
\hline pressure & $0.9 \mathrm{MPa}$ & $0.89 \mathrm{MPa}$ & $12.4 \mathrm{kPa}$ & 41 \\
\hline pressure & $1.38 \mathrm{MPa}$ & $1.36 \mathrm{MPa}$ & $23.4 \mathrm{kPa}$ & 78 \\
\hline pressure & $2.41 \mathrm{MPa}$ & $2.40 \mathrm{MPa}$ & $39.3 \mathrm{kPa}$ & 110 \\
\hline flow & $510 \mathrm{~kg} / \mathrm{m}^{2} / \mathrm{s}$ & $510.6 \mathrm{~kg} / \mathrm{m}^{2} / \mathrm{s}$ & $8.9 \mathrm{~kg} / \mathrm{m}^{2} / \mathrm{s}$ & 62 \\
\hline flow & $1020 \mathrm{~kg} / \mathrm{m}^{2} / \mathrm{s}$ & $1020.8 \mathrm{~kg} / \mathrm{m}^{2} / \mathrm{s}$ & $17.9 \mathrm{~kg} / \mathrm{m}^{2} / \mathrm{s}$ & 99 \\
\hline flow & $2040 \mathrm{~kg} / \mathrm{m}^{2} / \mathrm{s}$ & $2029.6 \mathrm{~kg} / \mathrm{m}^{2} / \mathrm{s}$ & $34.7 \mathrm{~kg} / \mathrm{m}^{2} / \mathrm{s}$ & 68 \\
\hline
\end{tabular}

Table 3. Statistics of Flow Conditions Studied

\subsection{Review of data and uncertainty analysis for two-phase multiplier and flow quality}

The two-phase multipliers determined from the pressure drop data will be plotted versus quality, as calculated using Eq. (38). The uncertainty in quality was determined via a propagation of errors analysis as follows:

$$
\begin{aligned}
\varepsilon_{x}{ }^{2}=\left[\frac{1}{\dot{m} h_{f g}}\right]^{2}\left[\varepsilon_{Q}{ }^{2}+\varepsilon_{Q_{\text {loss }}}{ }^{2}\right]+\left[\frac{\left(Q-Q_{\text {loss }}\right)}{h_{f g} \dot{m}^{2}}\right]^{2}\left[\varepsilon_{\dot{m}}{ }^{2}\right]+\left[\frac{C_{P}}{h_{f g}}\right]^{2}\left[\varepsilon_{T_{\text {in }}}{ }^{2}+\varepsilon_{T_{\text {sat }}}{ }^{2}\right]+ \\
{\left[\frac{x}{h_{f g}}\right]^{2} \varepsilon_{h_{f g}}{ }^{2}+\left[\frac{T_{i n}-T_{\text {sat }}}{h_{f g}}\right]^{2}\left[\varepsilon_{C_{P}}{ }^{2}\right] }
\end{aligned}
$$


The individual uncertainties for heat input, heat losses, flow rate, and inlet temperature is given in Table 2. The uncertainty in $h_{f g}$ and $C_{P}$ was estimated to be $+/-0.5 \%$, based on the uncertainty in system pressure of $+/-19.3 \mathrm{kPa}(+/-2.8 \mathrm{psi})$. Similarly, the uncertainty in $T_{\text {sat }}$ was taken to be $+/-0.83{ }^{\circ} \mathrm{C}$.

The uncertainty in two-phase multiplier is determined by examining the uncertainties in the measurements of the two-phase pressure drop as well as in the Blasius correlation used for the single-phase pressure drop. A series of test runs performed in single phase liquid flow were used to assess the accuracy of the Blasius correlation (Eq. (4)). The pressure gradients were measured in the upper window elevation in the test section (i.e., $\Delta \mathrm{P}_{3}$ in Fig. 2). The difference between the measured gradients and the predicted gradients using Eq. (4) are plotted in Fig. 3. The average difference is $0.05 \mathrm{kPa} / \mathrm{m}$ with a standard deviation of $0.38 \mathrm{kPa} / \mathrm{m}$ (the 2-phase multiplier and deviation is 1.002 and 0.17 respectively). The small average difference indicates that no clear bias is present in the single phase data compared to the Blasius correlation. The standard deviation is close to the measurement uncertainty in the $\Delta \mathrm{P}$ transducers and indicates no large additional random errors are present when measuring single phase liquid flow. The increase in pressure loss due to high aspect ratio geometry, noted by Jones (1976), was not observed here, possibly due to the differences in development lengths. 


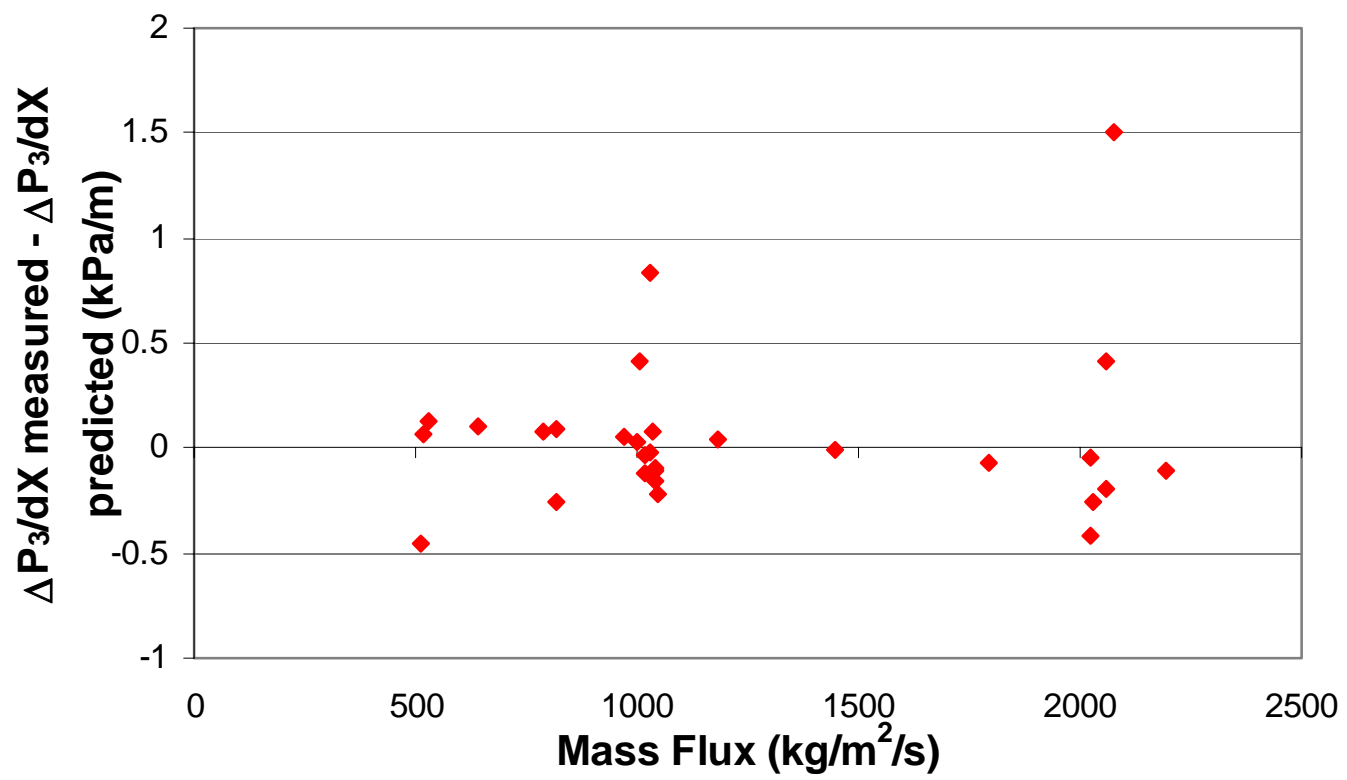

Figure 3. Pressure gradient comparisons for single phase flow (pressure transducer uncertainty $=0.33-0.42 \mathrm{kPa} / \mathrm{m}$ )

Some adiabatic two-phase pressure gradient data was available for the upper two window elevations $\left(\Delta \mathrm{P}_{3}\right.$ and $\Delta \mathrm{P}_{1}$ in Fig. 2) and are examined in Fig. 4. The difference between the measured gradient in the upper window $\left(\Delta \mathrm{P}_{3}\right)$ and the average between the upper two windows $\left(\Delta \mathrm{P}_{1}+\Delta \mathrm{P}_{3}\right) / 2$ is presented, normalized by the single phase frictional gradient (consistent with the definition of two-phase multiplier). The average of the difference is $-3.7 \%$ with a standard deviation of $13 \%$. This data indicates larger random uncertainty compared to the single phase data; however, there are other factors that may be potentially associated with this data, including flow development affects, spacing variations, and void fraction gradients in addition to potential vapor infiltration of the pressure lines. A very conservative estimate of the random uncertainty in measured pressure gradient in the 2-phase condition is taken to be the maximum of either the Rosemount transducer uncertainty or $+/-2 \sigma$, which is $+/-26 \%$ of the single phase pressure gradient at the particular flow condition. 


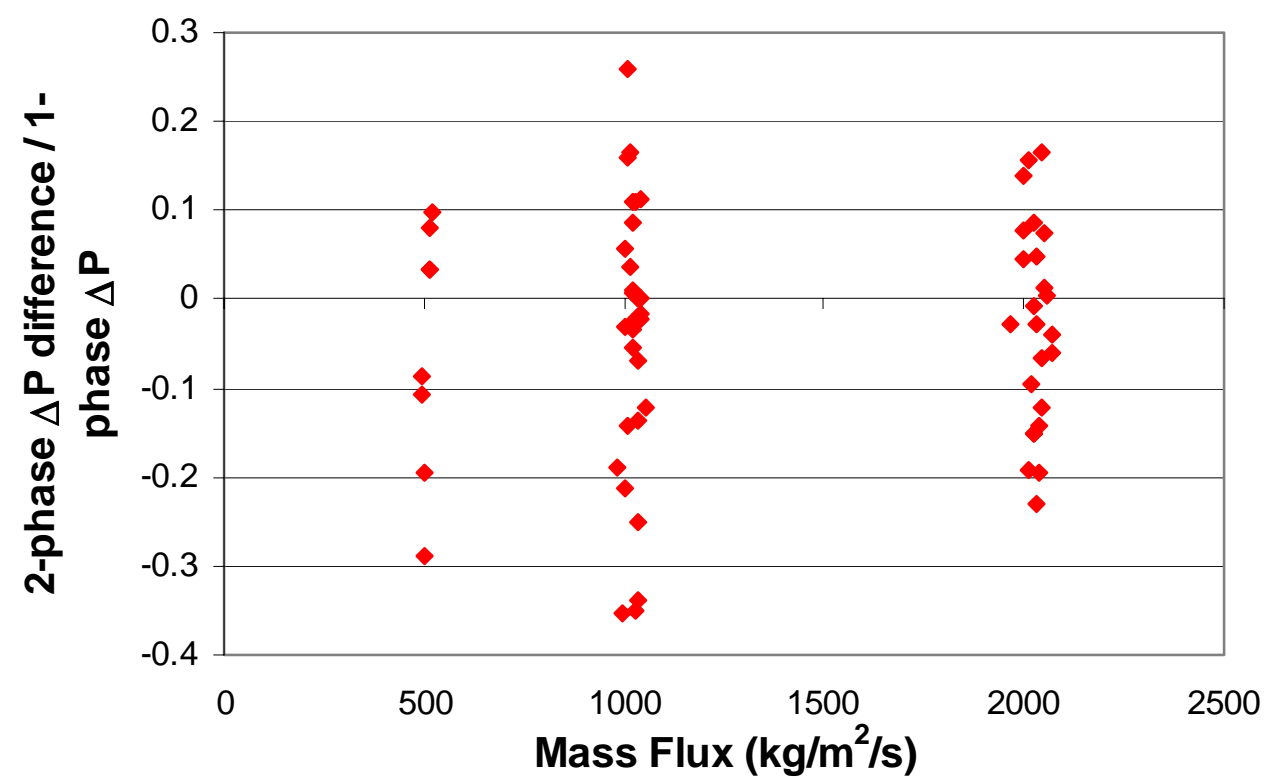

Figure 4. Normalized difference between two-phase $\Delta \mathrm{P}_{3}$ gradient and average gradient of $\Delta \mathrm{P}_{1}$ and $\Delta \mathrm{P}_{3}$.

Fig. 5 presents a comparison of the pressure gradients $\Delta \mathrm{P}_{1}$ and $\Delta \mathrm{P}_{3}$ as well as $\Delta \mathrm{P}_{2}$ and $\Delta \mathrm{P}_{3}$ for adiabatic data only. Error bars proportional to the random uncertainty magnitudes described above are included with the data. Most of the comparisons between the upper two window elevations $\left(\Delta \mathrm{P}_{1}\right.$ and $\left.\Delta \mathrm{P}_{3}\right)$ are within the random measurement uncertainty. The comparisons between $\Delta \mathrm{P}_{2}$ and $\Delta \mathrm{P}_{3}$ indicate an increased pressure gradient in the bridge insert between window elevations; this effect is especially evident at the higher flow rates where any misalignment between the insert and the window would be magnified. Fig. 6 shows GDS measurement comparisons in the upper two window elevations for the cases where these measurements are available. The agreement for the large majority of the measurements is within the random experimental uncertainty of the GDS (i.e., $+/-0.02$ absolute void as summarized in Table 2). 


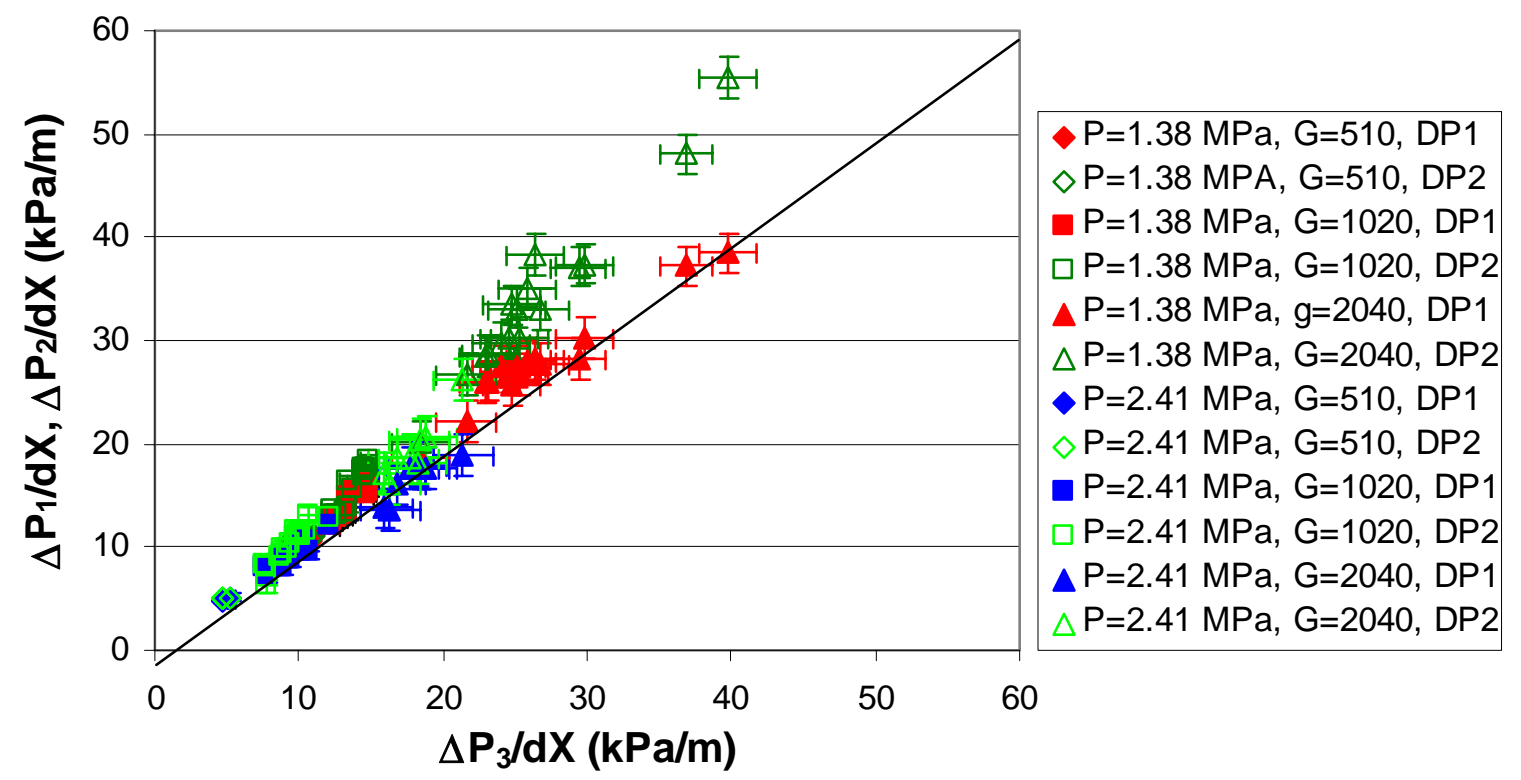

Figure 5. Pressure gradient comparisons. The mass flux, $\mathrm{G}$, has units of $\mathrm{kg} / \mathrm{m}^{2} / \mathrm{s}$.

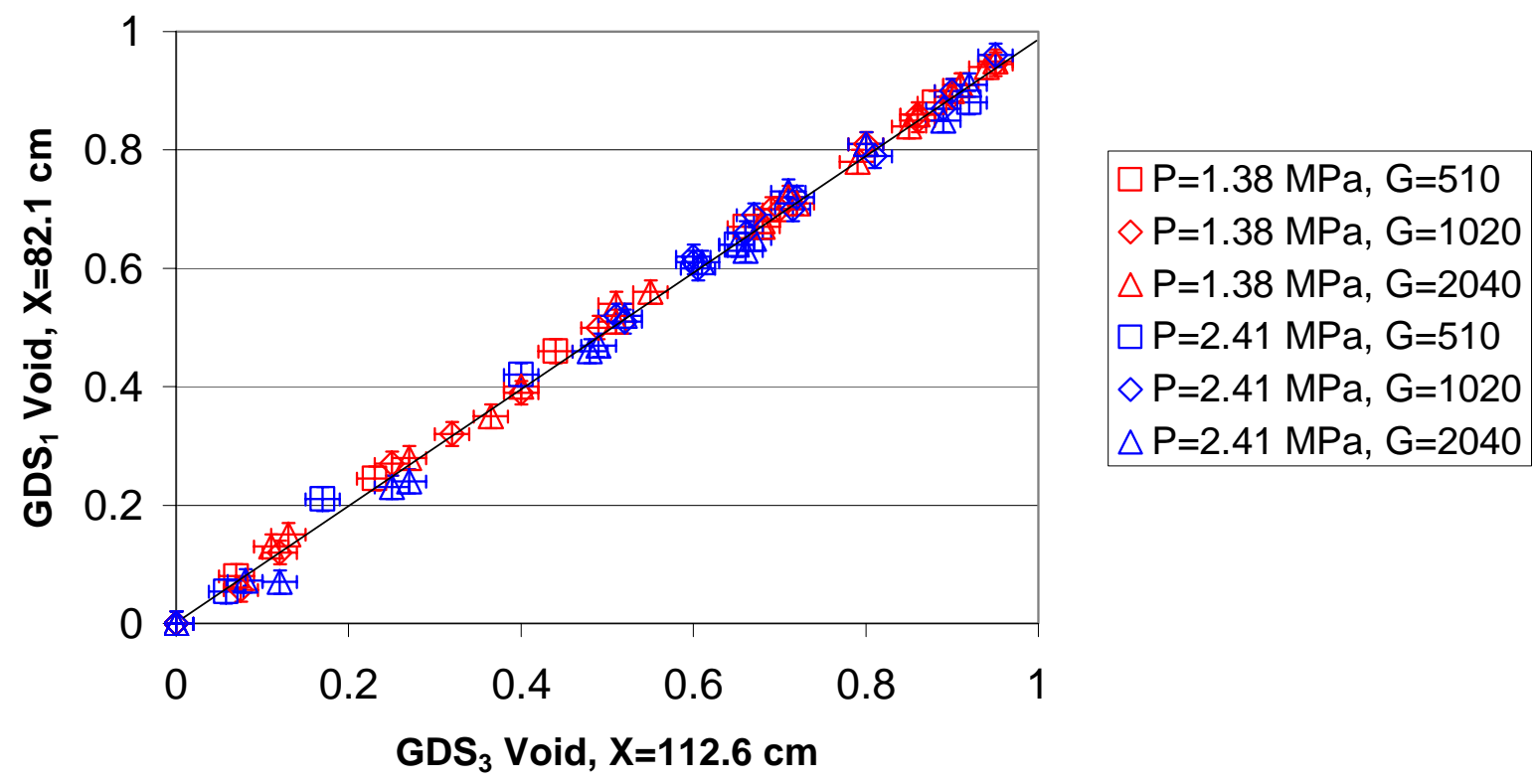

Figure 6. Void fraction comparisons. The mass flux, G, has units of $\mathrm{kg} / \mathrm{m}^{2} / \mathrm{s}$. 
It is noted that the frictional pressure drop component was obtained by subtracting the gravity head from the direct pressure drop measurements. Since the calculated gravity head depends on the average void fraction measured with the GDS, errors associated with the GDS will influence the measured $\Delta P_{f}$. The random part of the GDS uncertainty is incorporated in the $\Delta P_{f}$ uncertainty analysis, previously described. The bias uncertainty (given in Table 2) is also included in the error propagation to obtain the final uncertainty in $\Phi_{l o}{ }^{2}$ as follows:

$$
\frac{\varepsilon_{\Phi^{2}}}{\Phi^{2}}=\sqrt{\left[\frac{\varepsilon_{\Delta P_{\text {random }}}{ }^{2}}{\Delta P^{2}}+\frac{\varepsilon_{\Delta P_{\text {bias }}}{ }^{2}}{\Delta P^{2}}+\frac{\varepsilon_{D_{H}}{ }^{2}}{D_{H}{ }^{2}}+\frac{\varepsilon_{f}{ }^{2}}{f^{2}}+\frac{\varepsilon_{\rho}{ }^{2}}{\rho^{2}}+4 \frac{\varepsilon_{V}{ }^{2}}{V^{2}}\right]}
$$

where

$$
\varepsilon_{\Delta P_{\text {bias }}}=-0.03\left(\rho_{l}-\rho_{v}\right) g h
$$

and $\varepsilon_{\Delta P_{\text {random }}}$ is estimated as described previously. The relative uncertainty for the last four terms is between $+/-1$ and $+/-2 \%$.

\subsection{Data Comparisons to Reference Models}

The uncertainties in quality and two-phase multiplier, given by Eq. (39) and Eq. (40) respectively, were used to generate error bars for all the data points and are included in the data presented in Figs. 7-9. Each figure includes data for the three nominal flow rates $\left(510 \mathrm{~kg} / \mathrm{m}^{2} / \mathrm{s}, 1020 \mathrm{~kg} / \mathrm{m}^{2} / \mathrm{s}\right.$ and 2040 $\mathrm{kg} / \mathrm{m}^{2} / \mathrm{s}$ ) at a given nominal pressure (0.9 MPa, 1.38 MPa or 2.41 MPa). Both adiabatic and heated data, defined in Section 3, are included, although the large majority of points are for completely adiabatic runs. Also included in the figures are the predictive correlations discussed in Section 2.

The data sets most applicable to refrigeration systems are the low flow, low pressure results shown in Fig. 7, particularly $\mathrm{G}=510 \mathrm{~kg} / \mathrm{m}^{2} / \mathrm{s}$. This data shows reasonable agreement with both LockhartMartinelli and Chisholm, which is consistent with other published results (Jung and Radermacher, 1989; Tran et al., 2000). Overall, the data for 0.9 MPa shows good agreement with either the Baroczy 
or Chisholm models, both of which do the best job capturing the sensitivity to mass flux as observed in the data. The Friedel correlation does not reflect enough sensitivity to mass flux but does appear to be a reasonable measure of the average multiplier considering all three mass fluxes. The multipliers for $0.9 \mathrm{MPa}$ are all higher and, at times, significantly higher than the homogeneous prediction, perhaps indicating the presence of large interfacial velocity gradients contributing to large interfacial friction and shear. The density ratio between the liquid and gas phases for this pressure is about 28:1, which would lead to high relative velocities between phases throughout all pertinent flow regimes, including bubbly, slug and annular. The results for the heated data are consistent with the adiabatic data, indicating no clear dependence on flow development affects.

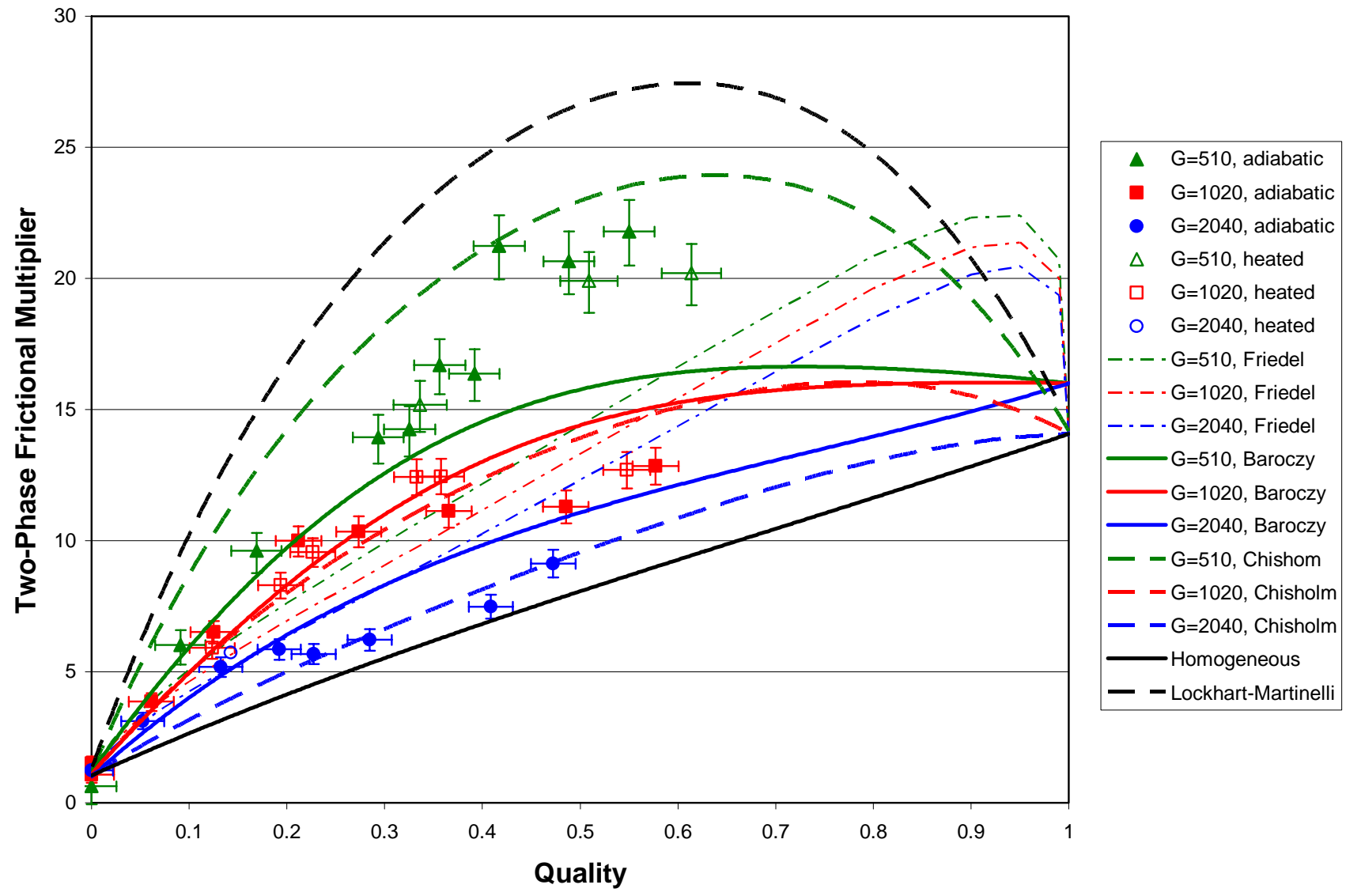

Figure 7. Two-phase frictional multipliers, $\mathrm{P}=0.9 \mathrm{MPa}$; data-model comparisons. The mass flux, $\mathrm{G}$, has units of $\mathrm{kg} / \mathrm{m}^{2} / \mathrm{s}$. 
The data comparisons for $\mathrm{P}=1.38 \mathrm{MPa}$ are shown in Fig 8 . In general, the trends here are similar to $\mathrm{P}=0.9 \mathrm{MPa}$ although the multiplier magnitudes are less. The decrease in magnitude is due primarily to the decrease in density ratio at this pressure (i.e., 16:1 vs. 28:1) Still, there is a wide range of multiplier level as a function of mass flux; at $\mathrm{G}=2040 \mathrm{~kg} / \mathrm{m}^{2} / \mathrm{s}$, the data is in line with the homogeneous prediction for $x>0.2$, while it is two to three times the homogeneous prediction at $\mathrm{G}=510 \mathrm{~kg} / \mathrm{m}^{2} / \mathrm{s}$.

The approach to the homogeneous prediction at higher flow rates is intuitively consistent with the expected decrease in relative velocity with increasing flow rate. The Lockhart-Martinelli model greatly overpredicts the data, while the Baroczy and Chisholm models again do the best overall job predicting the data for all flow rates. There appears to be a trend in the data where the multiplier dips at intermediate values of quality before rising again. This trend appears more evident as the flow rate increases. Similar behavior has been observed previously (see Vassallo et al., 2001) and was

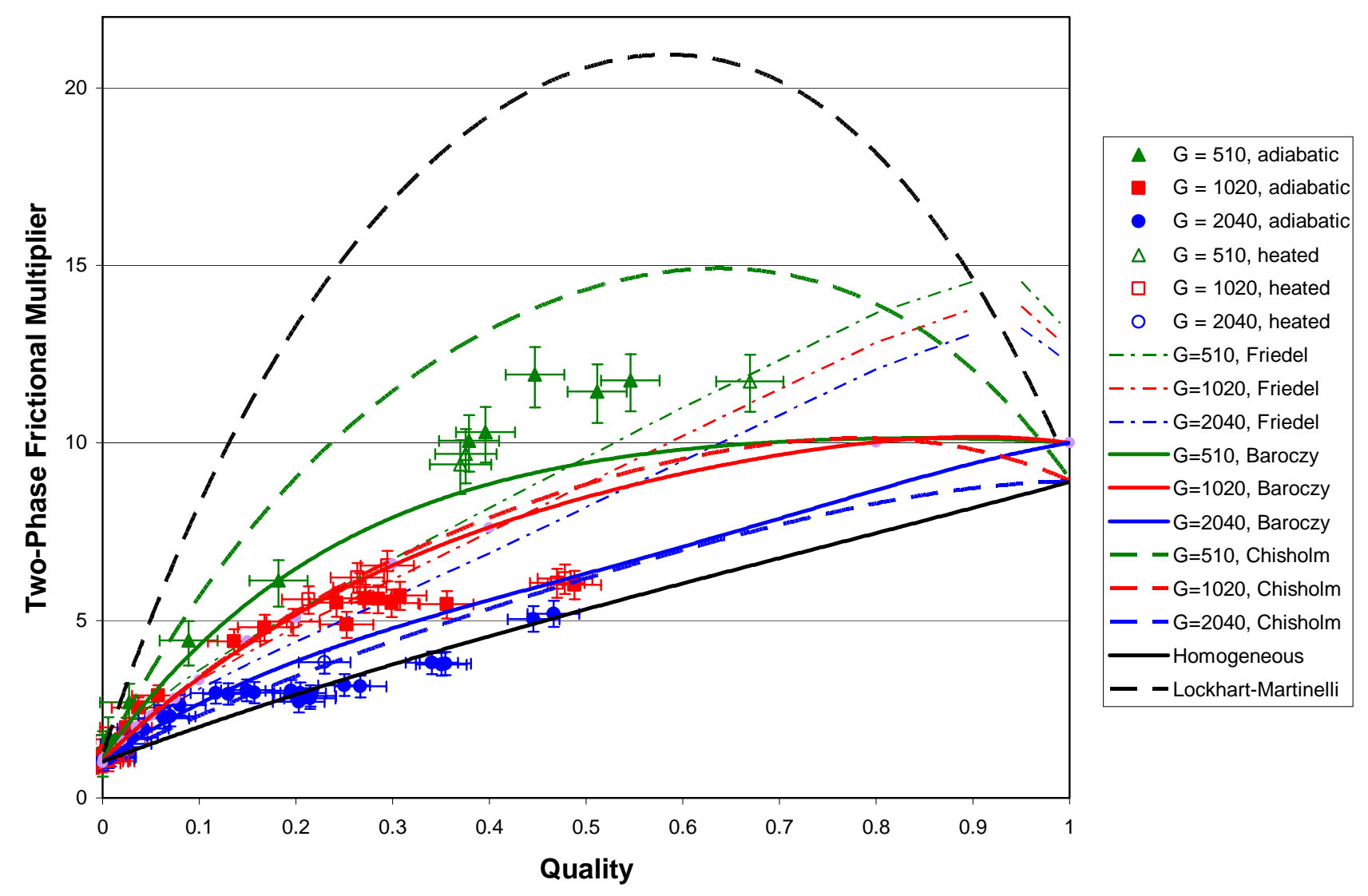

Figure 8. Two-phase frictional multipliers, $\mathrm{P}=1.38 \mathrm{MPa}$; data-model comparisons. The mass flux, G, has units of $\mathrm{kg} / \mathrm{m}^{2} / \mathrm{s}$. 
attributed to the flow regime change between the slug and annular flow regimes. In transitional flow, where flooding type waves may be present near the wall, a larger frictional gradient may be experienced compared to the higher quality conditions where annular flow begins to be established. Then, as the liquid film thins near the wall, an increase in quality will lead to an increase in two-phase pressure drop.

The dip in pressure gradient is also evident in the $\mathrm{P}=2.41 \mathrm{MPa}$ data, shown in Fig. 9. Interestingly, the $\mathrm{G}=1020 \mathrm{~kg} / \mathrm{m}^{2} / \mathrm{s}$ and $2040 \mathrm{~kg} / \mathrm{m}^{2} / \mathrm{s}$ data have nearly collapsed on each other and the bulk of this data lies very close to the homogeneous prediction. Some of the data appears to be less than the homogeneous prediction, which is consistent with the results from Miropolskii et al. (1965) for steamwater flow in tubes at $\mathrm{P}=2.85 \mathrm{MPa}$. The Chisholm correlation, which was usually within $30 \%$ of the data for the lower pressure conditions, is further removed here and is upwards of $100 \%$ high. This

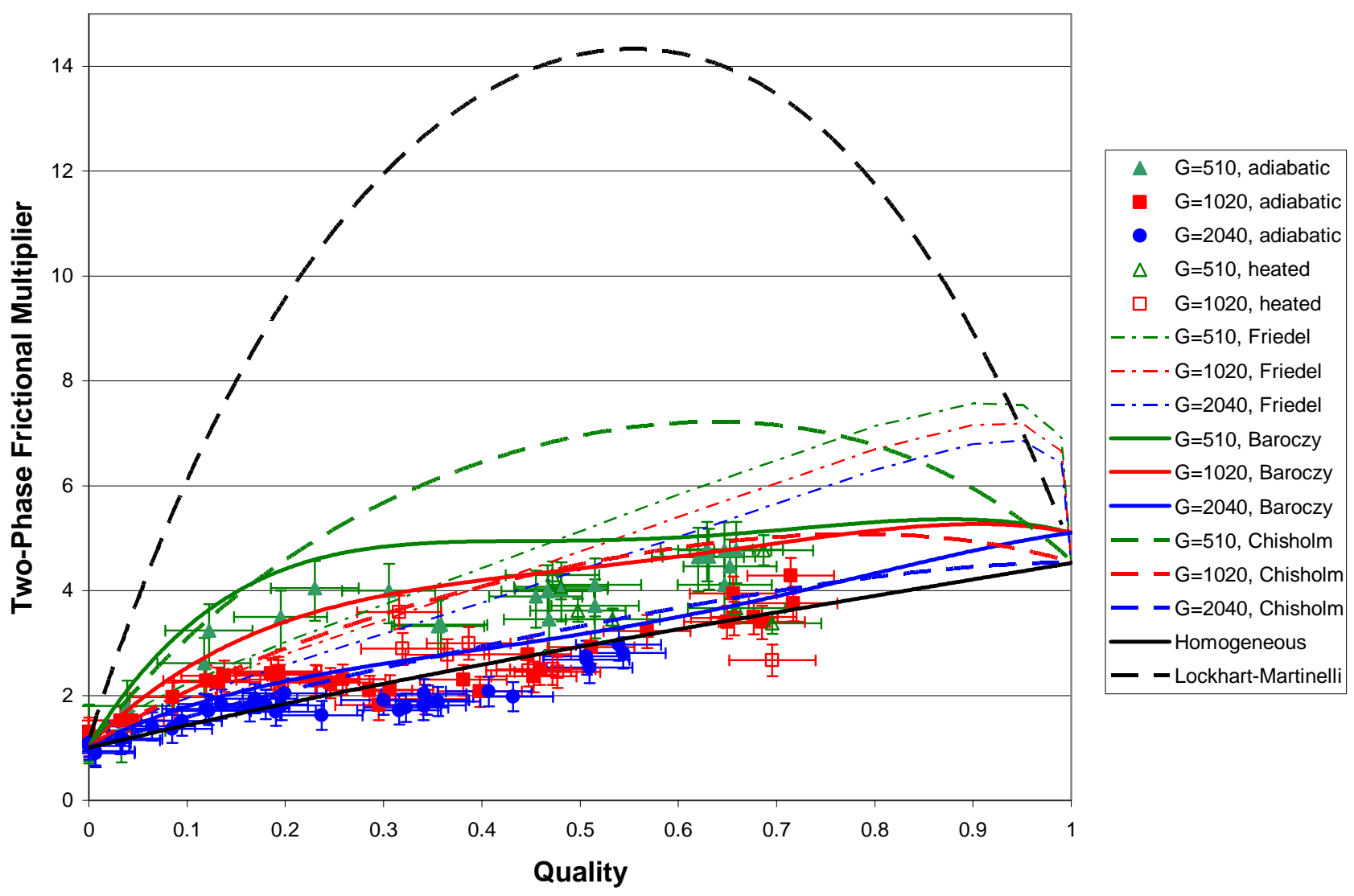

Figure 9. Two-phase frictional multipliers, $\mathrm{P}=2.41 \mathrm{MPa}$; data-model comparisons. The mass flux, $\mathrm{G}$, has units of $\mathrm{kg} / \mathrm{m}^{2} / \mathrm{s}$. 
may be due to the fact that for lower pressures the density difference effect on momentum may dominate the losses and is better captured by the model, while at the higher pressure (where the density ratio is about 7:1), other smaller effects (like surface tension affecting both bubble size and interfacial drag) may play a larger role and not be captured as well. Previous comparisons with higher pressure steam-water data (Idsinga et al., 1977) in fact showed that the homogeneous model performed very well and was recommended for general use along with the Baroczy correlation. Similar conclusions can be drawn from this data. The Lockhart-Martinelli model is not a good choice for this pressure.

Local void fraction SUVA data, summarized in Vassallo et al. (2001), indicates that the distribution of the liquid phase in annular type flows is highly dependant on system pressure. For example, at $\mathrm{G}=510 \mathrm{~kg} / \mathrm{m}^{2} / \mathrm{s}$ and $\mathrm{P}=0.9 \mathrm{MPa}$, there is significant liquid film on the walls, while at $\mathrm{G}=510 \mathrm{~kg} / \mathrm{m}^{2} / \mathrm{s}$ and $\mathrm{P}=2.41 \mathrm{MPa}$, there is much less film and a larger concentration of liquid droplets in the vapor core. Thus, the lower pressure condition acts more like a separated flow, which is consistent with the Lockhart-Martinelli analysis. This is shown in Fig. 7, including the characteristic of a maximum in the two-phase multiplier at quality $\sim 60 \%$ and a downward approach to the all vapor multiplier at $100 \%$ quality. On the other hand, the higher pressure condition acts more like a homogeneous vapordroplet flow, with multipliers generally increasing with quality. This is consistent with the data shown in Fig. 9.

A void-quality plot for $\mathrm{P}=2.41 \mathrm{MPa}$ is shown in Fig. 10. Also included in the figure is the homogeneous model prediction for comparative purposes, which is given as:

$$
\alpha=\frac{1}{\left[1+\left(\frac{1-x}{x}\right)\left(\frac{\rho_{v}}{\rho_{l}}\right)\right]}
$$


It is seen that the data is consistent with the model trendline and that the void fraction sensitivity to mass flux is reasonable. That is, as the mass flux decreases at a given quality, the increase in slip leads to a decrease in void fraction and an increased departure from the homogeneous model. The curve also illustrates that high void fractions are quickly achieved at relatively low quality, which is consistent with the previous observation that transitional flow occurs near qualities of $20 \%$ (corresponding to void fractions near 60\%). The annular flow regime (i.e., void fractions greater than about $80 \%$ ) occur for a large range of qualities, which is consistent with the data provided in Figs. 7-9.

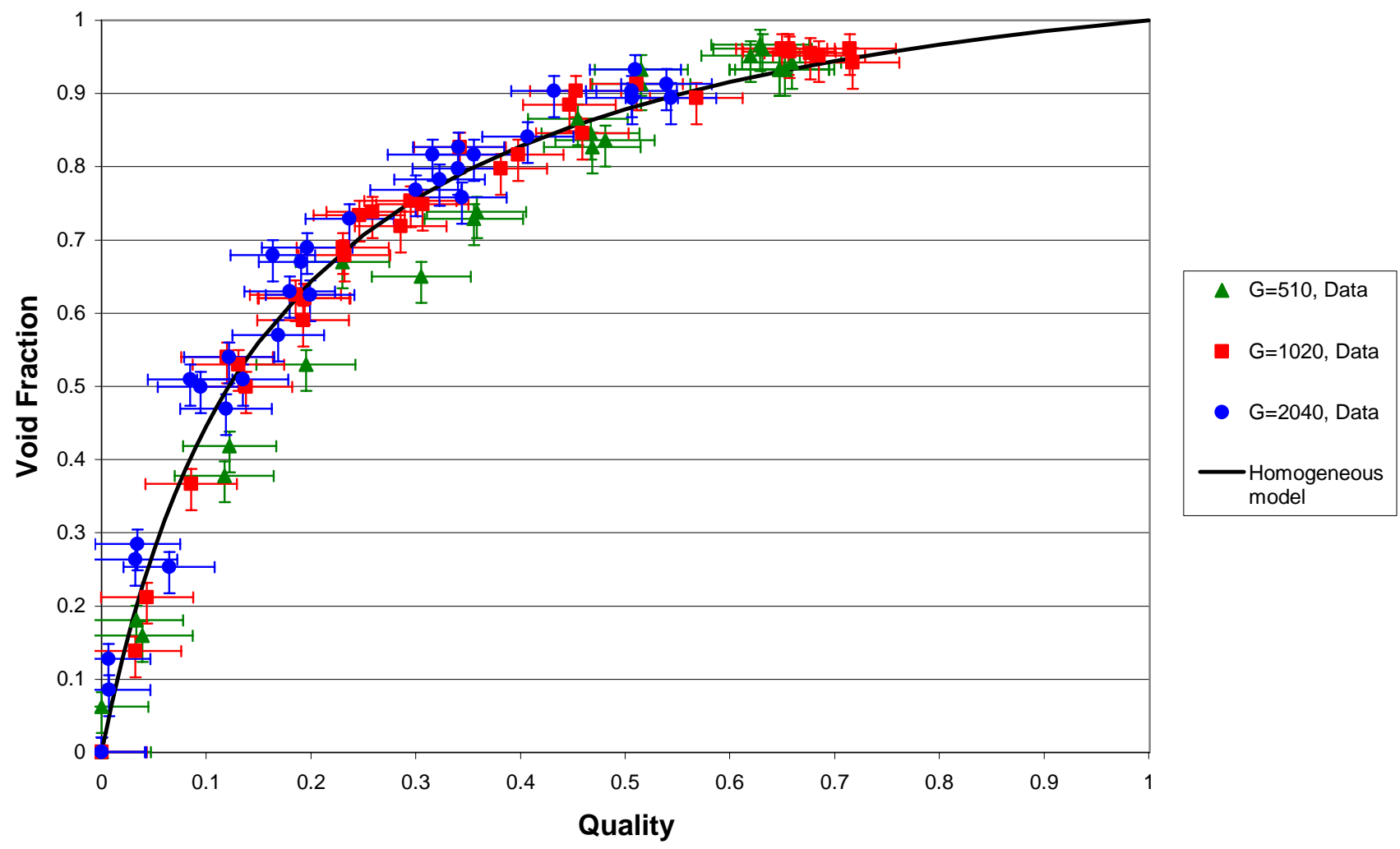

Figure 10. Void-quality relationship for $\mathrm{P}=2.41 \mathrm{MPa}$; data-model comparisons. The mass flux, $\mathrm{G}$, has units of $\mathrm{kg} / \mathrm{m}^{2} / \mathrm{s}$.

Table 4 summarizes the average difference and average deviation between the predictive models and data for each pressure and mass flux. Two-phase multiplier values for the Lockhart-Martinelli, Chisholm, Friedel and homogeneous models were calculated explicitly at the calculated quality for 
each data point while a fifth order polynomial was fitted to the Baroczy prediction to obtain those particular values. The highlighted regions in Table 4 indicate conditions where the average difference between model and data was less than about $25 \%$.

\section{Flow Conditions}

\begin{tabular}{l|ccccccccccc} 
Model & \multicolumn{1}{c}{$\mathrm{L}, \mathrm{L}$} & $\mathrm{L}, \mathrm{M}$ & $\mathrm{L}, \mathrm{H}$ & $\mathrm{M}, \mathrm{L}$ & $\mathrm{M}, \mathrm{M}$ & $\mathrm{M}, \mathrm{H}$ & $\mathrm{H}, \mathrm{L}$ & $\mathrm{H}, \mathrm{M}$ & $\mathrm{H}, \mathrm{H}$ \\
\cline { 2 - 10 } Chisholm & $\underline{\underline{0.22(.12)}}$ & $\underline{0.0(.14)}$ & $\underline{0.13(.18)}$ & $\underline{0.17(.18)}$ & $\underline{0.07(.18)}$ & $\underline{0.06(.18)}$ & $0.55(.26)$ & $0.40(.30)$ & $\underline{0.21(.19)}$ \\
Baroczy & $\underline{-0.16(.09)}$ & $\underline{0.0(.16)}$ & $\underline{0.13(.18)}$ & $\underline{-0.15(.087}$ & $\underline{0.05(.17)}$ & $\underline{0.16(.19)}$ & $\underline{0.21(.17)}$ & $0.47(.32)$ & $\underline{0.24(.16)}$ \\
Homogeneous & $-0.58(.03)$ & $-0.36(.14)$ & $\underline{-0.18(.13)}$ & $-0.47(.12)$ & $\underline{-0.26(.14)}$ & $\underline{-0.04(.15)}$ & $-0.30(.10)$ & $\underline{-0.07(.17)}$ & $\underline{0.08(.15)}$ \\
Friedel & $-0.30(.06)$ & $\underline{-0.07(.16)}$ & $\underline{0.17(.17)}$ & $\underline{-0.21(.05)}$ & $\underline{0.05(.16)}$ & $0.36(.23)$ & $\underline{0.18(.22)}$ & $0.45(.32)$ & $0.51(.27)$ \\
Lockhart- & $0.43(.15)$ & $0.87(.42)$ & $1.85(.48)$ & $0.66(.34)$ & $1.29(.79)$ & $2.64(1.16)$ & $2.10(.60)$ & $3.35(1.22)$ & $4.0(1.6)$ &
\end{tabular}

Table 4. Average difference and average standard deviations (in parenthesis) for each model vs. data. The flow conditions are summarized as low, medium or high pressures (i.e., $L=0.9$ MPA, $M=1.38 \mathrm{MPA}, \mathrm{H}=2.41 \mathrm{MPa}$ ) followed by low, medium and high mass fluxes (i.e., $\mathrm{L}=510 \mathrm{~kg} / \mathrm{m}^{2} / \mathrm{s}, \mathrm{M}=1020 \mathrm{~kg} / \mathrm{m}^{2} / \mathrm{s}, \mathrm{H}=2040 \mathrm{~kg} / \mathrm{m}^{2} / \mathrm{s}$ ). Thus, L,M refers to the condition with $\mathrm{P}=0.9 \mathrm{MPa}$ and $\mathrm{G}=1020 \mathrm{~kg} / \mathrm{m}^{2} / \mathrm{s}$. The underlined entries indicate flow conditions where the average difference was less than about $25 \%$.

\section{Conclusions}

An examination of two-phase frictional pressure drop in adiabatic SUVA, R-134a has revealed a significant dependency on system pressure and mass flux. The range of pressure and mass flux considered was $0.9 \leq P \leq 2.4 \mathrm{MPa}$ and $510 \leq G \leq 2040 \mathrm{~kg} / \mathrm{m}^{2} / \mathrm{s}$. At low pressure and mass flux, the flow is highly separated and the two-phase multiplier is adequately described by a LockhartMartinelli type analysis. At high pressure and mass flux, the flow is mostly homogeneous and the two-phase multiplier is best described by a homogeneous model. The best models for the entire range of pressures and mass flux studied are either Baroczy or Chisholm, although the Chisholm 
model, being an explicit equation, is more readily useful. The manner in which the voids were generated (i.e., either upstream of the test section or within the test section itself) had little affect on the measured frictional pressure gradient in the unheated exit portion of the test section. This data may be used to augment and extend existing databases for adiabatic SUVA two-phase flow, that, in general, have been focused on lower mass fluxes and pressures.

\section{References}

Baroczy, C.J., 1968. A systematic correlation for two-phase pressure drop. Chem. Eng. Prog. Symp. Series No. 64, 232-249.

Chisholm, D, 1973. Pressure gradients due to friction during the flow of evaporating two-phase mixtures in smooth tubes and channels. Int. J. Heat Mass Transfer, 16, 347-358.

Friedel, L, 1979. Improved friction pressure drop correlations for horizontal and vertical two-phase pipe flow. European Two-Phase Flow Group Meeting, Paper E2, Ispra, Italy.

Garimella, S., Killion, J.D., Coleman, J.W., 2003. An experimentally validated model for two-phase pressure drop in the intermittent flow regime for circular microchannels. J. Fluids Eng., 124, 205-214.

Idsinga, W., Todreas, N. and Bowring R., 1977. An assessment of two-phase pressure drop correlations for steam water systems. Int. J. Multiphase Flow, 3, 401-413.

Jones, O.C., 1976. An improvement in the calculation of turbulent friction in rectangular ducts", J. Fluids Eng., 98, 173-181.

Jung, D.S., Radermacher, R., 1989. Prediction of pressure drop during horizontal annular flow boiling of pure and mixed refrigerants. Int. J. Heat Mass Transfer, 32, 2435-2446.

Kirouac, G.J., Trabold, T.A., Vassallo, P.F., Moore, W.E., Kumar, R., 1999. Instrumentation development in two-phase flow. Exp. Thermal Fluid Science, 20, 79-93.

Kumar, R., Trabold, T.A., and Maneri, C.C., 2003. Experiments and modeling in bubbly flows at elevated pressures. J. Fluids Eng., 125, 469-478.

Lockhart, R.W., Martinelli, R.C., 1949. Proposed correlation of data for isothermal two-phase, two component flow in pipes. Chem. Eng. Prog. 45, 39-48.

Martinelli, R.C., Nelson, D.B., 1948. Prediction of pressure drop during forced-circulation boiling of water. Trans. ASME. 70, 695-702.

McAdams, W.H., Woods, W.K., Bryan, R.L., 1942. Vaporization inside horizontal tubes - II Benzene-Oil Mixtures. Trans. ASME, 64, 193. 
Miropolskii, E.L., Shitsman, M.E. and Shneenova, R.I., 1965. Influence of heat flux and velocity on hydraulic resistance with steam-water mixture flowing in tubes. Thermal Engineering, 12, 80.

Ould, M.B., Kattan, N., Thome, J.R., 2002. Prediction of two-phase gradients of refrigerants in horizontal tubes. Int. J. Refrigeration, 25, 935-947.

Stahl, P., and von Rohr, P.R., 2004. On the accuracy of void fraction measurements by single beam gamma-densitometry for gas-liquid two-phase flows in pipes. Exp. Thermal and Fluid Science, 28, 533-544.

Trabold, T.A., Kumar, R. and Vassallo, P.F., 1999. Experimental study of dispersed droplets in high pressure annular flows. J. Heat Transfer, 121, 924-933.

Tran, T.N., Wambsganss, M.W., France D.M., 1996. Small circular and rectangular channel boiling with two refrigerants. Int. J. Multiphase Flow, 22, 485-498.

Tran, T.N., Chyu, M-C, Wambsganss, M.W., France D.M., 2000. Two-phase pressure drop of refrigerants during flow boiling in small channels: an experimental investigation and correlation development. Int. J. Multiphase Flow, 26, 1739-1754.

Vassallo, P.F., Trabold, T.A., Kumar, R. and Considine, D.M., 2001. Slug-to-annular regime transitions in R-134a flowing through a vertical duct. Int. J. Multiphase Flow, 27, 119-145. 


\section{Professor Trygvasson,}

Enclosed is the manuscript Two-phase frictional pressure drop multipliers for SUVA R134-a flowing in a rectangular duct revised in accordance with the Reviewers' suggestions. The text changes are highlighted in red. We would like to thank you and the reviewers for your comments and suggestions. Most of the comments were addressed and incorporated into the revised version of the paper and have resulted in a stronger, more accurate paper. The specific responses to each reviewers' comments are provided next.

\section{Reviewer \#1}

We have modified the discussion on page 3 to more accurately state that many previous studies of two-phase pressure drop occurred in heated flows where an estimate (using models) of the void fraction gradient was necessary to remove the acceleration pressure drop component. Here, the testing was restricted to adiabatic pressure gradient data where the acceleration component could be neglected and is now noted as such on page 3. Also the direct use of GDS to remove the gravitational component is introduced here as well.

The reviewer is correct in stating that various errors are associated with the GDS technique. Although they are relatively small for our measurements, we have done a better job characterizing these errors and have included them in the uncertainty analysis. The biases are now detailed on pages 13 and 14 and a more thorough uncertainty analysis is provided on page 20 . As there appeared to be some confusion on the manner in which the GDS beam interrogated the flow field, a schematic depiction of the GDS device with respect to the measurement axes in the test section have been added to Fig. 2 and clarifications made in the text on page 12. The densitometer was calibrated using a liquid SUVA filled test section and an evacuated test section, as described on page 12 to obtain the appropriate calibration constants. A void-quality data plot has been added that shows reasonable agreement with analytical results across the entire range of void fraction (from 0 to $95 \%$ void) to provide another measure of GDS qualification.

Although the explicit form of Eq. (9) is not given in Lockhart-Martinelli's paper, the equation (with C=20 for turbulent flow) faithfully follows the mean curve presented in the same paper relating $\Phi^{2}{ }_{l}$ to $X_{\mathrm{tt}}$ and thus captures the essence of Lockhart-Martinelli's original work. This formulation has been called Lockhart-Martinelli in several references [1],[2], including Carey [3] which presents the model exactly as we do. Other references have slightly different values on the exponents in $\mathrm{X}_{\mathrm{tt}}$ because their 
treatments use $n=0.2$ for the friction factor exponent rather than $n=0.25$ used here. We believe $\mathrm{n}=0.25$ is more appropriate since it is consistent with the Blasius formulation and fits our all liquid pressure drop data well. To be more accurate in the discussion, we have modified the description of the correlation on page 5 to indicate that the $\Phi^{2}{ }_{l}$ curve in Lockhart-Martinelli's paper can be written as shown in Eq. 9.

The Chisholm B-coefficient model has appeared in numerous recent papers dealing with two-phase frictional pressure drop, including [1],[2] and [4]. We like the model because it incorporates the fluid parameter sensitivity observed by Baroczy and because it is in a useful form which lends itself to straightforward application. We feel it performs well over the range of conditions studied and, since it is being increasingly used by contemporary researchers, feel it is the appropriate Chisholm model to include.

The thermocouple rakes were installed to measure the fluid temperature entering either the inlet heaters or the test section window heaters. As described on page 9, for the bulk of the data, the voids were created upstream of the test section and, for this data, the test section inlet temperature was not needed. The test section inlet temperature was considered for the "heated" data, where the voids were created in the first $3 / 4$ of the test section by directly heating the fluid with the window heaters. In either case, the inlet temperatures to the heaters were used to account for the small liquid subcooling in the quality calculation, as seen in Eq. 38 on page 15 . This subcooling was less than $10^{\circ} \mathrm{C}$ and has now been noted as such in the discussion on page 10. The "trim" heaters and "inlet" heaters refer to the same heaters in the inlet lines leading into the test section; to remove the understandable confusion, these heaters are now exclusively referred to as "inlet heaters" in the text. The heat loss sensitivity to flow rate was observed during calibration runs. The heat loss increased somewhat with flow, most likely due to improved heat transfer coefficients inside the test section as the flow rate increased.

With respect to flow development, a statement was added on page 8 that frictional pressure drop comparisons in the last two test section elevations supports the claim of developed flow for the purpose of pressure drop analysis.

\section{Reviewer \#2}

This reviewer numbered his suggestions and we will address each in the same numbered fashion. In many instances, the suggestion was implemented directly and is reflected as such.

1) Incorporated on page 1, in the Abstract.

2) Incorporated on page 2.

3) Clarified on page 8.

4) Clarified on page 8.

5) Clarified on page 10.

6) Corrected.

7) All of our $\Delta \mathrm{P}$ data was taken in the unheated exit portion of the test section where the wall heat flux was zero. The gravity component of the $\Delta \mathrm{P}$ measurement was calculated directly using GDS measured average void fraction data. For the large majority of the data, the voids were created using heaters well upstream of the test section while for a smaller data set, the voids were created in the first $3 / 4$ of the test section (described on page 9 ). The difference between these data sets would be development length before the $\Delta \mathrm{P}$ measurement. Within the data scatter, no clear development effects were observed, as described on page 21 and in the conclusions.

8) We agree with this format and have implemented accordingly. 
9) This was incorrectly stated (since bias errors in GDS void fraction were not originally considered) and is now dealt with accurately on page 20.

10) Clarified on pages 17 and 18.

11) We agree and have modified the figures accordingly.

12) We don't have enough visual results to produce an accurate flow pattern map. We did add a void-quality plot (Fig. 10 on page 26) which qualitatively illustrates potential flow regimes as a function of void fraction and provides evidence that the qualities remarked upon do correspond to void fractions in a transitional range.

13) The purpose of the analysis was to show the explicit form for calculating uncertainties for the key parameters of interest (i.e., quality and two-phase multiplier) which were included in Figs. 7-9. The magnitude of the uncertainties varies with flow, pressure, heat loss, inlet temperature, etc and is difficult to quantify in a succinct manner. Instead, the uncertainties were calculated for each data point using Eqs. (39) and (40) and pertinent experimental parameters and were included in the figures.

14) Conclusions have been added.

15) Done.

We hope the revised paper is found to be satisfactory. We again thank the Reviewers for their work and believe that incorporating their comments have strengthened the paper.

Let me know if you require anything further,

Peter Vassallo

\section{$\underline{\text { References }}$}

[1] Wen, DS and Kenning, DBR, 2004. Two-phase pressure drop of water during flow boiling in a vertical narrow channel. Exp. Thermal and Fluid Science, 28, 131-138.

[2] Ould, M.B., Kattan, N., Thome, J.R., 2002. Prediction of two-phase gradients of refrigerants in horizontal tubes. Int. J. Refrigeration, 25, 935-947.

[3] Carey, V, 1992. Liquid-vapor phase change phenomena. Taylor and Frances.

[4] Tran, T.N., Chyu, M-C, Wambsganss, M.W., France D.M., 2000. Two-phase pressure drop of refrigerants during flow boiling in small channels: an experimental investigation and correlation development. Int. J. Multiphase Flow, 26, 1739-1754. 